\title{
Geographic distribution and socio-economic determinants of women's nutritional status in Mali households
}

\author{
Constance A Gewa ${ }^{1, *}$, Timothy F Leslie ${ }^{2}$ and Lisa R Pawloski ${ }^{1}$ \\ 'Department of Nutrition and Food Studies, College of Health \& Human Services, George Mason University, \\ 10340 Democracy Lane MSN 1F8, Fairfax, VA 22030, USA: ${ }^{2}$ Department of Geography and Geoinformation \\ Science, College of Science, George Mason University, Fairfax, VA, USA
}

Submitted 14 May 2012: Final revision received 16 August 2012: Accepted 23 August 2012: First published online 17 0ctober 2012

\begin{abstract}
Objective: Mali is one of the poorest countries in Africa, with $72 \%$ of its population surviving on less than \$US 1.00 per day. Health and demographic indicators are bleak. With few exceptions, studies related to the health of women in Mali have largely been under-represented. In addition, in recent years a new type of malnutrition stemming from weight gain and obesity has been observed throughout Africa. The present study aimed to (i) describe geographic and health variations of women of reproductive age, (ii) describe geographic variations of household salt iodine levels and (iii) investigate potential factors associated with women's anthropometric status and use of adequately iodized salt among households in Mali.

Design: Demographic and Health Survey data, multistage-stratified cluster sampling methodology.

Setting: Rural and urban areas of Mali.

Subjects: Non-pregnant women ( $n$ 6015) between the ages of 19 and 44 years.

Results: Nineteen per cent of the women were overweight or obese while $11 \%$ were underweight. Seventy-eight per cent of the households utilized adequately iodized salt. Underweight women were more prevalent in southern Mali, while obesity was more frequent in the north-east and within the major urban areas. Households located within the southern parts of Mali were more likely to utilize adequately iodized salt. Education, age, modern contraceptive use, breast-feeding status at time of the survey and household wealth index were significantly associated with the women's BMI or households' use of adequately iodized salt.

Conclusions: The combined use of statistical and geographic system analysis contributes to improve targeting of interventions among vulnerable populations.
\end{abstract}

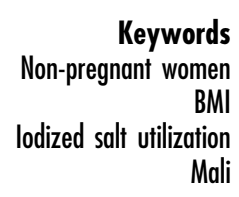

Mali is one of the poorest countries in Africa, with $72 \%$ of its population surviving on less than \$US 1.00 per day. Health and demographic indicators are bleak; life expectancy from birth is $49 \cdot 8$ years and maternal mortality is 580 per 100000 people. Several studies including the most recent national analysis from the Demographic and Health Surveys (DHS) examining the nutritional situation of children throughout Mali have shown significant numbers of stunted and wasted children ${ }^{(1)}$. Further, the WHO reports that approximately $30 \%$ of children under 5 years of age are underweight, $40 \%$ are stunted and about $4 \%$ are overweight $^{(2)}$. Recent research has shown evidence of poor nutrition among adolescent girls in Mali, suggesting that poor nutritional status is not a risk limited to childhood but extends into adolescence ${ }^{(3,4)}$. Most of the studies concerning the nutritional situation in Mali have focused primarily on infants and children and have ignored adolescents and adults. With the exception of studies related to infant feeding, reproductive health and violence against women, studies related to the health of women in Mali have largely been under-represented. Other field studies in Mali are generally dated and focus on children and infant feeding ${ }^{(5,6)}$. Dettwyler ${ }^{(7)}$ reported that while Malian women revealed evidence of stunting, they actually were better off nutritionally compared to Malian men, suggesting that women in Mali may experience some degree of buffering from environmental stresses.

In Mali, as in many countries in Sub-Saharan Africa, a woman's worth is based on her ability to have children ${ }^{(8)}$. Grosz-Ngate states many Malians believe the inherent weakness of womanhood is seen to be a handicap only for women who are "worthless", who are lazy ... and ... [a] woman can rise above the disadvantages of her gender by excelling in her tasks ${ }^{,(8)}$. Because of their primary roles as child-bearers and care-providers, women's health status has the potential to impact on the health of other household members. Maternal nutritional status has been shown to impact on breast-milk production and quality 
and to be a significant predictor of children's nutritional and health status in both developed and less-developed nations $^{(9-13)}$. The major types of malnutrition affecting women throughout Africa include chronic and acute undernutrition with an increasing trend of overweight and obesity in wealthier Sub-Saharan Africa ${ }^{(14-16)}$. Deficiencies of micronutrients such as Fe, vitamin $\mathrm{A}$ and iodine are common ${ }^{(17-19)}$. Maternal iodine deficiency has been associated with reproductive failure, poor fetal growth and mental development, and child mortality ${ }^{(20)}$. Thus poor nutritional status not only affects the physical health of a woman but it may also impact her emotional health and social standing. Adequately iodized salt has been identified as a cost-effective strategy to prevent and treat iodine-deficiency disorders. The present study aimed to (i) describe geographic and health variations of women of reproductive age, (ii) describe geographic variations of household salt iodine levels and (iii) investigate potential factors associated with women's anthropometric status and use of adequately iodized salt among households in Mali.

\section{Materials and methods}

\section{Participants}

We used the most recent DHS available, conducted in 2006, for our analysis. The DHS are intended to be nationally representative and provide data for a wide range of monitoring and impact evaluation indicators in the areas of population, health and nutrition. We selected women between the ages of 19 and 44 years. The lower age of 19 years was chosen as it marks the end of adolescent growth and the upper limit of 44 years was used to avoid including women past their reproductive years. Pregnant women (determined based on self-reports as collected by the DHS enumerators) were removed so that the complicating nutritional aspects of pregnancy did not bias our results. We further excluded data from households with multiple women so that these households were not oversampled. These reductions to the DHS data set resulted in a sample size of 6015 women. The DHS protocol was approved by ORC Macro's Institutional Review Board. Individuals with at least secondary school education who are fluent in the language of the interview were trained to conduct DHS interviews and measurements. Quality control team members were trained to observe interviews/ measurements and to conduct daily review meetings with the interviewers ${ }^{(21)}$.

\section{Women's antbropometry}

Interviewers were trained to conduct anthropometry measurements in teams of two. Training occurred over a period of $3 \mathrm{~d}$ and included classroom and field-based demonstrations in nearby kindergarten and health facilities $^{(22)}$. Anthropometry measurements were taken at the women's homes in an area with adequate lighting and level floor. Women were not required to fast prior to measurements. Weight was measured to the nearest $0 \cdot 01 \mathrm{~kg}$ using a lightweight bathroom-style SECA digital scale (Hamburg, Germany). Height was measured using a Shorr height board (Olney, MD, USA). Participants were measured wearing light clothing and without shoes. BMI was computed as weight in kilograms divided by the square of height in metres $\left(\mathrm{kg} / \mathrm{m}^{2}\right)$. BMI cut-offs were based on the recommended international cut-offs as follows: underweight was defined as $\mathrm{BMI}<18.5 \mathrm{~kg} / \mathrm{m}^{2}$, normal body weight as $\mathrm{BMI}=18 \cdot 5-24.9 \mathrm{~kg} / \mathrm{m}^{2}$, overweight as BMI $=25 \cdot 0-29 \cdot 9 \mathrm{~kg} / \mathrm{m}^{2}$ and obese was defined as $\mathrm{BMI} \geq 30 \cdot 0 \mathrm{~kg} / \mathrm{m}^{2}$. Women with a height below $150 \mathrm{~cm}$ were identified as being of short stature.

\section{Adequate salt iodine}

Household salt iodine levels were reported in parts per million (ppm). Households with salt iodine levels less than or equal to $15 \mathrm{ppm}$ were categorized as having inadequate household salt iodine levels.

\section{Housebold wealtb}

The DHS wealth index factor score was used as a household wealth indicator. The wealth index is based on all household assets. Each asset was assigned a factor score generated through principal components analysis, and the resulting asset scores were standardized in relation to a normal distribution with a mean of zero and standard deviation of one. Each household was then assigned a score for each asset and the scores were summed for each household. The sample was then divided into quintiles from one (lowest) to five (highest) ${ }^{(1)}$. The DHS wealth index allows for the identification of problems particular to the poor, such as unequal access to health care, as well as those particular to the wealthy, such as, in Africa, increased risk of HIV infection ${ }^{(23)}$.

\section{Women's education}

We defined a two-level variable to indicate women who reported no years of education and those who reported any years of schooling. There is a relatively large body of literature showing improved nutritional status following increased education in Africa and other developing countries, and thus the mother's education level can have an impact on nutritional status ${ }^{(24,25)}$.

\section{Breast-feeding status}

Women were asked if they were breast-feeding at the time of the survey. Lactation is associated with higher energy and nutrient demands on mothers; failure to meet these demands may lead to poor maternal nutritional status ${ }^{(26,27)}$.

\section{Modern contraceptives}

We defined a two-level categorical variable to identify women who used a least one form of modern contraceptives and those who did not. Women with greater 
numbers of births have been shown to suffer from additional health and nutritional complications ${ }^{(28)}$. Modern contraception use could also be a proxy for modernity and utilization of health services.

\section{Number of wives}

Number of wives within each household was identified. Many households in Mali are polygynous, allowing for up to five wives ${ }^{(29)}$. Some literature on Mali reports that additional wives, servants and children are a resource that may in fact improve the nutritional status of a family, as the household load is spread over a greater number of individuals ${ }^{(19)}$. It is possible that additional wives may also require more food within the household and their contributions may not outweigh this need, leading to a net loss for the household ${ }^{(30)}$.

\section{Number of births in the last 5 years}

We used the number of births in the last 5 years to account for the burden of bearing children. Women with greater numbers of births have been shown to suffer from additional health and nutritional complications ${ }^{(28)}$. High values could indicate greater nutritional and economic stress on a woman, and we expect this variable to have a negative effect on nutritional status and BMI. BMI is an indicator of acute malnutrition, which favours our decision to focus on the last 5 years.

\section{Women's age}

Women's age in completed years was calculated from the participants' date of birth and the date of interview. Age is an important control because in reference populations adults' weight typically increases as they age, particularly during mid-life due to decreased mobility and lean muscle mass ${ }^{(31)}$. Previous research in Mali documented that women may lose weight as they age, particularly through adolescence ${ }^{(4)}$.

\section{Cartographic analysis}

Cartographic analysis was used to provide a broader understanding of factors influencing nutritional status in Mali. We created continuous surfaces across Mali of the variables of interest in order to highlight differences across the country and reveal broad locational patterns. Interpolation provides predicted values so that aspects of health, nutrition and socio-economic behaviour can be examined at a national level, instead of providing snapshots of the 'clusters' of households located in close proximity (with precise individual locations obscured by DHS to preserve respondent anonymity). The 408 'clusters' of geographic survey locations denoted by the DHS for several variables of interest are used in an inverse-distance process that predicts values based on the values of surrounding points, weighting nearby locations more than those further away ${ }^{(32)}$. A smoothing process was incorporated into this calculation so that local surface variations that would exaggerate data precision were removed $^{(33)}$. Estimation surfaces were cut off at the borders of Mali to the west, south and east, and by the northernmost observations. Estimates are less confident further away from DHS collection points.

The number of individual observations in each cluster ranged from three to twenty-six, with an average of fifteen. We mapped modelled variables, including the percentages of overweight and households with adequately iodized salt. Our other maps, including births in the last 5 years and breast-feeding status, are explanatory variables for differences in nutritional status. Legend groupings were determined using a natural breaks method. DHS clusters are included in the map to indicate areas of greater uncertainty.

\section{Data analysis}

We modelled women's nutritional status using three variables: BMI, overweight/obese indicator and underweight indicator. Additionally, we assessed factors associated with adequate household salt iodine levels in Mali. The SAS statistical software package version $9 \cdot 2$ was used for data analysis. Survey analysis procedures are appropriate for complex survey study designs and were utilized to help estimate sampling errors. SAS procedures SURVEYFREQ, SURVEYMEANS, SURVEYREG and SURVEYLOGISTIC were used to estimate means, percentages, linear regression coefficients and odds ratios. Linear regression analysis was used to assess the relationship between selected independent variables and women's BMI. Logistic regression analysis was used to assess the odds of a woman being overweight/obese or underweight and the household using adequately iodized salt. Independent variables included women's age, education, use of modern contraceptives and breast-feeding status; household wealth and location (urban or rural); number of other wives and number of births in the last 5 years. Including women's stature in the regression model did not bring about any changes to the results and a decision was made to exclude the height variable from the regression analysis. Variables came together as a multivariate model of the following form:

$$
\begin{aligned}
\text { DEPENDENT }_{i}= & \alpha+\beta_{1} \text { AGE }_{i}+\beta_{2} \text { BREAST-FEEDING }_{i} \\
& +\beta_{3} \text { RESIDENCE }_{i}+\beta_{4} \text { WEALTH }_{i} \\
& +\beta_{5} \text { MODERN-CONTRACEPTIVE }_{i} \\
& +\beta_{6} \text { BIRTH-LAST-5-YEARS }_{i} \\
& +\beta_{7} \text { NUMBER-WIVES }_{i} \\
& +\beta_{8} \text { EDUCATION }_{i}+\varepsilon_{i}
\end{aligned}
$$

Non-response across variables, particularly concerning the number of other wives in a family, reduced the effective sample size to 5668 in the regression analysis.

\section{Results}

\section{Descriptive statistics}

Mean women's age was 29.60 (SD 0.10) years (Table 1 ). Mean BMI was $22 \cdot 37(\mathrm{SD} 0 \cdot 09) \mathrm{kg} / \mathrm{m}^{2}$. Approximately $19 \%$ 
were overweight or obese and $10 \%$ were underweight. Over $78 \%$ of the households consumed salt with adequate iodine levels. Mean height was $161(\mathrm{sD} 0 \cdot 001) \mathrm{cm}$.

Table 1 Health and socio-economic characteristics among nonpregnant women aged 19-44 years: Demographic and Health Survey data, Mali, 2006†,‡

\begin{tabular}{lrc}
\hline & Mean or \% & $95 \% \mathrm{Cl}$ \\
\hline Age (years) $\S$ & $29 \cdot 60$ & $29 \cdot 41,29 \cdot 80$ \\
Height $(\mathrm{cm}) \S$ & $161 \cdot 34$ & $161 \cdot 09,161 \cdot 59$ \\
Height $<150 \mathrm{~cm}(\%)$ & $3 \cdot 12$ & $2 \cdot 51,3 \cdot 73$ \\
BMI $\left(\mathrm{kg} / \mathrm{m}^{2}\right) \S$ & $22 \cdot 37$ & $22 \cdot 19,22 \cdot 54$ \\
Overweight (\%) & $18 \cdot 88$ & $17 \cdot 32,20 \cdot 43$ \\
Underweight (\%) & $10 \cdot 22$ & $9 \cdot 28,11 \cdot 17$ \\
Adequate salt iodine level (\%) & $78 \cdot 19$ & $75 \cdot 37,81 \cdot 01$ \\
Received formal education (\%) & $16 \cdot 92$ & $15 \cdot 32,18 \cdot 52$ \\
Births in last 5 years $\S$ & $1 \cdot 33$ & $1 \cdot 30,1 \cdot 36$ \\
Breast-feeding (\%) & $54 \cdot 33$ & $52 \cdot 94,55 \cdot 73$ \\
Use of modern contraception (\%) & $8 \cdot 37$ & $7 \cdot 31,9 \cdot 42$ \\
Number of other wives $\S$ & $0 \cdot 31$ & $0 \cdot 29,0 \cdot 34$ \\
Urban residence (\%) & $38 \cdot 71$ & $32 \cdot 91,44 \cdot 50$ \\
Wealth index (\%) & & \\
First quintile & $18 \cdot 04$ & $15 \cdot 54,20 \cdot 55$ \\
Second quintile & $19 \cdot 52$ & $17 \cdot 60,21 \cdot 44$ \\
Third quintile & $20 \cdot 75$ & $19 \cdot 07,22 \cdot 43$ \\
Fourth quintile & $20 \cdot 34$ & $17 \cdot 99,22 \cdot 69$ \\
Fifth quintile & $21 \cdot 34$ & $18 \cdot 25,24 \cdot 43$ \\
\hline
\end{tabular}

tn 6015 .

‡Estimates are percentages $(95 \% \mathrm{Cl})$, unless otherwise indicated.

$\S$ Estimates are mean $(95 \% \mathrm{Cl})$ values.
Just over $3 \%$ of the women had a height below $150 \mathrm{~cm}$. Only $8 \%$ of the women reported using at least one form of modern contraceptives. Number of births in the last 5 years ranged from 0 to 5 , with a mean of $1 \cdot 33$ (SD $0 \cdot 01$ ). Twenty-one per cent of the women reported no births in the last 5 years. About $54 \%$ of the women were breastfeeding at the time of the survey. Women's education level was relatively low, with only $17 \%$ of the women reporting having at least a primary level of education. Number of other wives ranged from 0 to 4 with a mean of $0 \cdot 31$ (SD $0 \cdot 01$ ). Over $72 \%$ of the women interviewed claimed no other wife was present in the household. A majority of the women resided within rural parts of Mali with only $39 \%$ living within urban areas.

\section{Cartographic analysis}

Figure 1 shows the interpolated surface for the percentage of the population that is overweight. Estimated values ranged from a low of $11 \%$ in the south to over $60 \%$ of the population in the north-west. As a general trend, the population changed in a relatively linear manner along a north-east-south-west axis. Bamako and Timbuktu showed a higher prevalence of high-BMI women compared with the surrounding regions. However, Mopti showed no increase in high-BMI women. The surface of the underweight

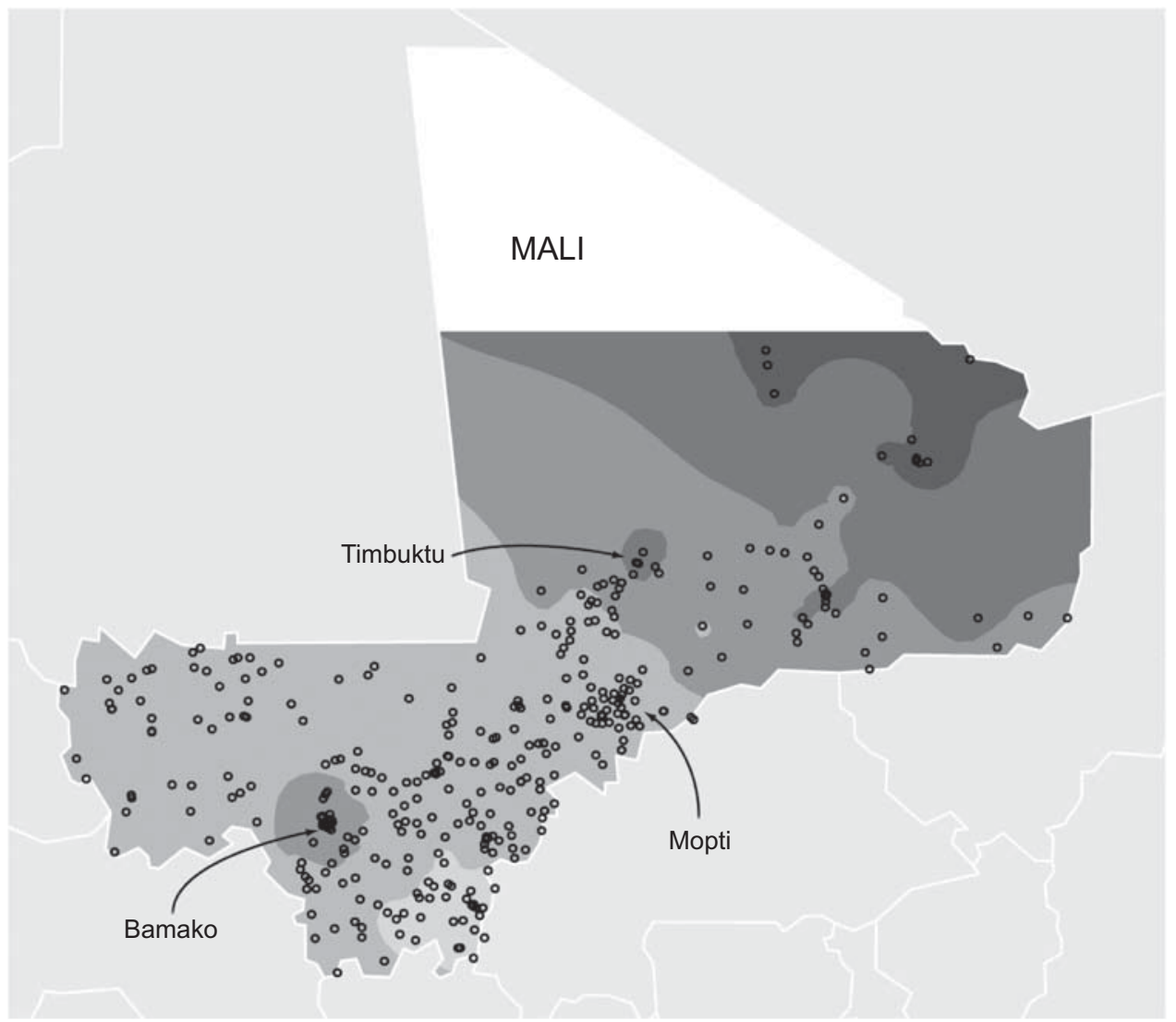

Fig. 1 Interpolated surface of overweight levels among non-pregnant women aged 19-44 years by cluster, Demographic and Health Survey (DHS) data, Mali, 2006. Frequency of overweight $\left(\mathrm{BMI} \geq 25 \cdot 0 \mathrm{~kg} / \mathrm{m}^{2}\right): \quad, 11 \cdot 38-15 \cdot 39 \%$; , 15.40-21.25\%; , 21.26-29.83\%; , 29.84-42.37\%; , 42.38-60.11\%. O indicate DHS cluster sample locations 


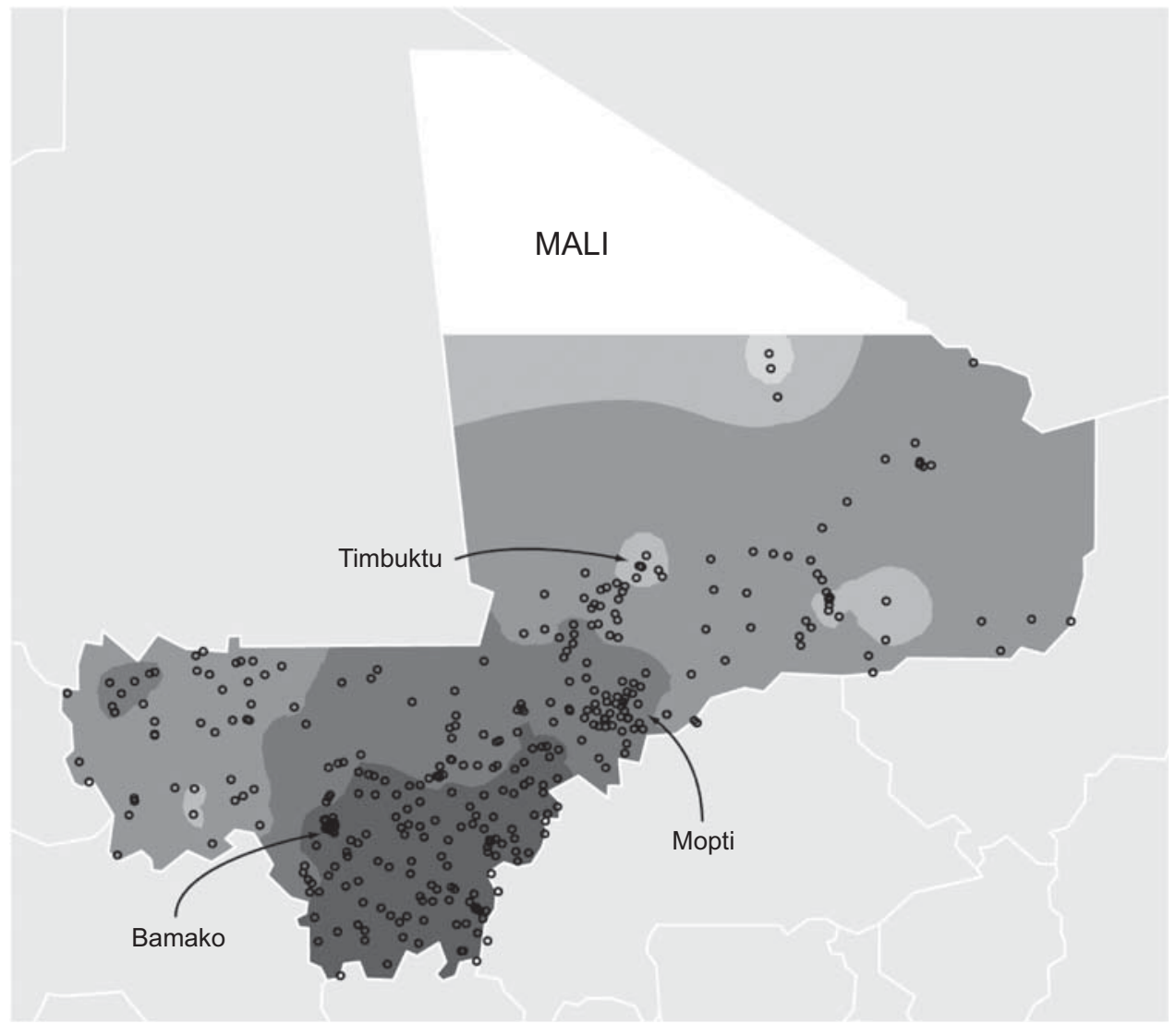

Fig. 2 Interpolated surface of adequately iodized household salt levels among non-pregnant women aged 19-44 years by cluster, Demographic and Health Survey (DHS) data, Mali, 2006. Frequency of homes with adequate household salt: , 40.00-54.32\%; , 54.33-65.79\%; , 65.80-75.01\%; , 75.02-82.40\%; _, 82.41-88.34\%. ○ indicate DHS cluster sample locations

population was almost an exact inverse. Our second modelled variable, adequately iodized household salt, is shown in Fig. 2. This variable appeared to radiate away from positive values in the south of the country, decreasing to the north-west and north-east. Timbuktu showed a lower percentage of households with adequately iodized salt compared with the surrounding regions. Bamako and Mopti showed no differences from the surrounding areas. Four localities, Timbuktu, Kita and Gao included, had the lowest percentage of households consuming adequately iodized salt. Figure 3 shows the estimated average number of births for each woman in the last 5 years across the country. Birth loads within the last 5 years were highest in the south, except in Bamako. Values generally decreased to the northeast and to the west, with one point in the west having an extremely low value. Highly reproductive areas had $18-44 \%$ more children in the last 5 years than the least reproductive areas. Figure 4 shows the interpolated levels of breast-feeding frequency across Mali. It was largely an inverse of high-BMI women (Fig. 2), having the high values in the south and low values in the north-east. Bamako and Timbuktu had lower levels of breast-feeding than the surrounding region, while Mopti had higher levels. Our final variable map in Fig. 5 shows the distribution of modern contraception users across Mali. Contraception use was highest in Bamako and regions nearby in the south-west, as well as in the far north-east.

\section{Regression analysis}

Having formal education, use of modern contraceptives, increase in woman's age and higher household wealth index were each associated with significantly higher BMI values (Table 2). Mean BMI among women with some formal education was 0.98 points higher than that among women with no formal education. Mean BMI value among women using modern contraceptives was 0.65 points higher than that of non-users and a 1-year increase in women's age was associated with an increase of 0.08 points in BMI. There was a dose-response effect with mean BMI values rising with wealth index categories. Mean BMI among women living in households within the highest wealth index was $2 \cdot 74$ points higher than that of women living in households within the lowest wealth index. No significant differences were noted between the last two wealth index categories. Breast-feeding at time of the study was associated with significantly lower BMI values. The mean BMI value among women who were breast-feeding at the time was 0.39 points lower than that of women who 


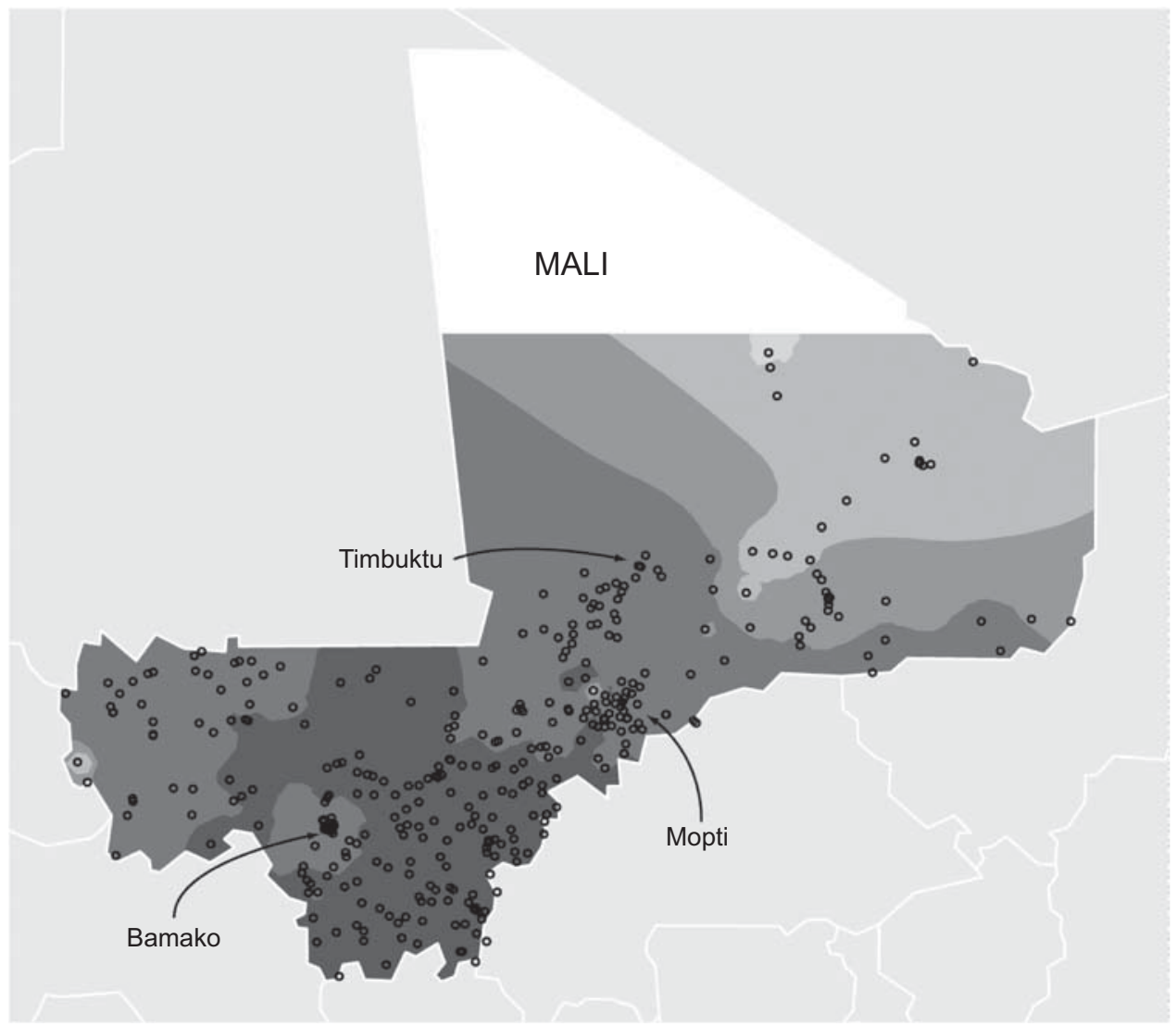

Fig. 3 Interpolated surface of the average number of births in the last 5 years among non-pregnant women aged 19-44 years by cluster, Demographic and Health Survey (DHS) data, Mali, 2006. Average number of births in the last 5 years: , 0.991-1.111; , 1.112-1.187;, $1 \cdot 188-1 \cdot 235 ; \quad, 1 \cdot 236-1 \cdot 311 ; \ldots, 1 \cdot 312-1 \cdot 431$. $\bigcirc$ indicate DHS cluster sample locations

were not breast-feeding. Residence location (urban/rural), number of other wives and number of births in the last 5 years did not predict women's BMI. Our regression model explained $12 \cdot 23 \%$ of the variability in women's BMI.

The overweight/obese regression model results were consistent to a certain extent with the overall BMI model (Table 3). Women's age, having some formal education and household wealth index were each associated with higher odds of being overweight or obese, while breastfeeding status at time of study was associated with significantly lower odds of being overweight or obese. One-year increase in women's age was associated with 1.06 odds of being overweight or obese. Women with formal education were associated with 1.65 odds of being overweight or obese compared with those without any formal education. Women from households categorized within the third, fourth and fifth wealth index quintiles were each associated with $2 \cdot 28,3 \cdot 15$ and $6 \cdot 12$ odds of being overweight or obese compared with women in households categorized within the first wealth index quintile. Residence location (urban/rural), number of other wives and number of births in the last 5 years did not predict overweight or obesity among this group of women. Unlike the BMI model, use of modern contraceptives did not significantly predict overweight/obesity.
Only one variable in our regression model predicted women's underweight. A one-unit increase in number of births in the last 5 years was associated with significantly lower odds of being underweight.

Only two variables were significantly associated with adequate household salt iodine. Women with formal education and women who utilized modern contraceptives were associated with 1.33 and 1.49 odds of living in households with adequately iodized salt, respectively.

Our logistic regression models explained $15 \cdot 75 \%$ of the variability in women's overweight/obesity status, $1 \cdot 81 \%$ of the variability in women's underweight status and $1.97 \%$ of the variability in utilization of adequately iodized household salt. There was no statistically significant association between women's BMI and household use of adequately iodized salt.

\section{Discussion}

The cartographic analyses provide an interesting presentation of health indicators in Mali. Underweight women were more prevalent in southern Mali, while obesity was more frequent in the north-east. Women in major urban areas were more likely to be obese than 


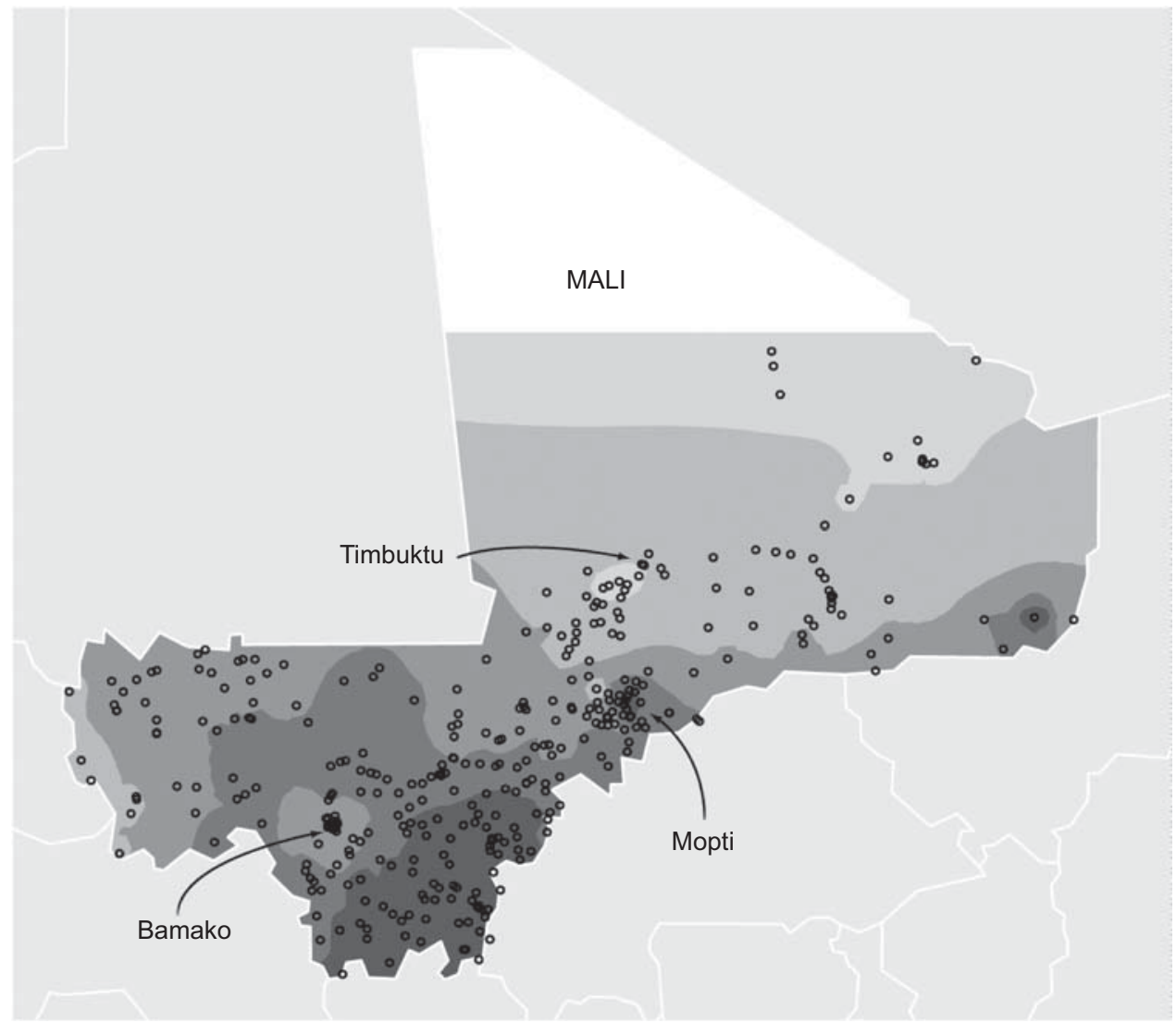

Fig. 4 Interpolated surface of breast-feeding frequency among non-pregnant women aged 19-44 years by cluster, Demographic and Health Survey (DHS) data, Mali, 2006. Frequency of breast-feeding: , 38.54-46.07\%; , 46.08-50.83\%; , 50.84-53.84\%; —, 53.85-56.85\%; — 56.86-61.61\%. ○ indicate DHS cluster sample locations

their rural counterparts. Our findings are supported by other reports of greater overweight individuals in urban regions of Sub-Saharan Africa ${ }^{(34)}$. As overweight populations increase, spatial representations like maps inform practitioners by guiding efforts to fight obesity and malnutrition. Similar methodology has been used to guide public health intervention in malaria prevention and access to modern contraceptives and other healthcare resources ${ }^{(35-37)}$. Our cartographic analyses concur with results of the recent DHS that reported overweight and obesity prevalence was highest among women living in urban areas and in Kidal region in the northeastern part of the country and the city of Bamako, while underweight prevalence was highest among women living in rural areas and in Sikasso and Gao regions in the southern and north-western parts of the country ${ }^{(1)}$. Household use of adequately iodized salt appears to be a function of household proximity to Cote d'Ivoire. Sikasso, Bamako and parts of Koulikoro regions had the highest percentage of households with adequately iodized salt. Although Mali imports iodized salt from Senegal ${ }^{(38)}$, only $54-66 \%$ of the households located in close proximity to Senegal (Kayes region) were shown to have adequately iodized salt.
The regression analyses suggest, not surprisingly, that wealth is a key indicator in the nutritional status of women in Mali. These results agree with some previous research in $\mathrm{Mali}^{(7,24)}$, but differ from a recent analysis in Mali based on a local socio-economic index ${ }^{(4)}$. The findings that women with more education were less likely to be underweight and were more likely to come from households that utilized adequately iodized salt support intervention efforts to keep girls in school ${ }^{(39)}$.

Results for age show that women became heavier as they aged. This association could potentially be due to multiple factors including pregnancy and weight retention associated with child birth, survivor bias against lowweight women especially in poor nations like Mali, and the general metabolic slow-down associated with age. Use of modern contraceptives was positively associated with women's BMI and household use of adequately iodized salt. Previous research has shown that modern contraceptive users tend to have higher education levels and exposure to information in media and to come from wealthier households ${ }^{(40)}$. Because our analysis has adjusted for education and wealth index, the noted 'modern contraceptive use' effect on BMI and use of adequately iodized salt goes beyond these two factors and may be an indicator 


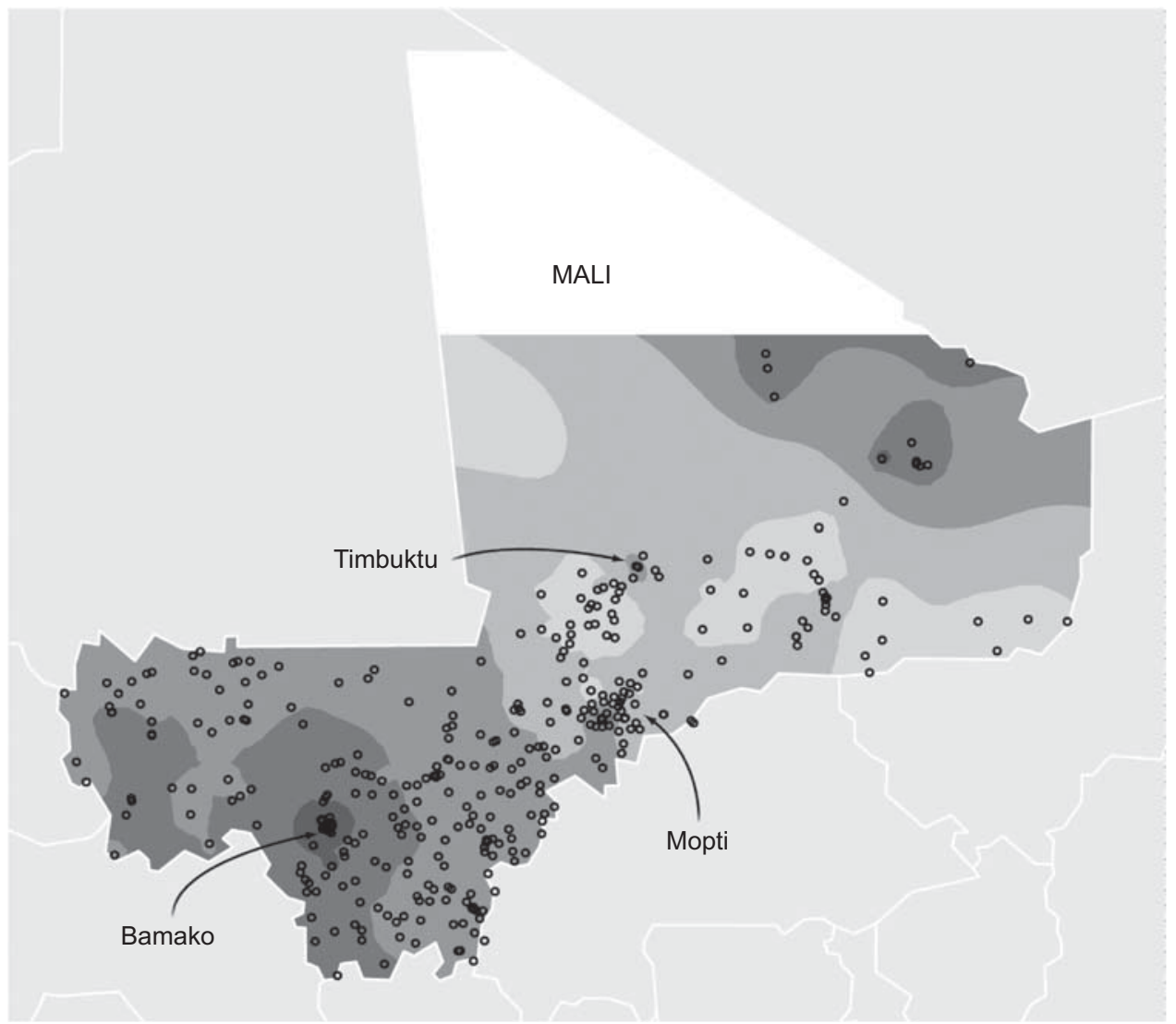

Fig. 5 Interpolated surface of the frequency of modern contraception use among non-pregnant women aged 19-44 years by cluster, Demographic and Health Survey (DHS) data, Mali, 2006. Frequency of use of modern contraception: , 3.43-5.98\%; , 5.99-7.87\%; —, 7.88-10.41\%; _, 10.42-13.85\%; —, 13.86-18.49\%. O indicate DHS cluster sample locations

Table 2 Socio-economic, demographic and health determinants of BMI $\left(\mathrm{kg} / \mathrm{m}^{2}\right)$ among non-pregnant women aged 19-44 years: Demographic and Health Survey data, Mali, 2006+, $\neq$

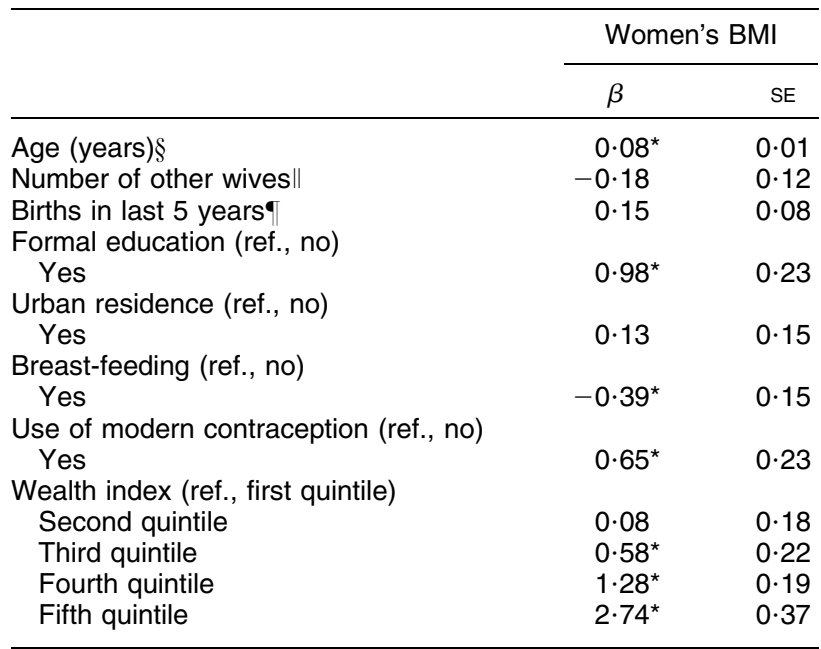

ref., reference category.

${ }^{*} \beta$ estimates were statistically significant $(P<0.05)$.

tn 5668 .

$\ddagger \beta$ and $95 \% \mathrm{Cl}$ values are estimates from a single multiple regression model that include all variables shown in the table.

$\S \beta$ values computed for a 1 -year increase in women's age.

$\| \beta$ values computed for one additional wife in the household.

$\uparrow \beta$ values computed for one additional birth in the last 5 years. of access, awareness or acceptance of modern health-care practices. A general lack of awareness of existing programmes or products such as iodized salt may lead to lower levels of demand and use, and cultural preference for locally produced non-iodized salt may also hinder consumption of the imported iodized salt ${ }^{(41)}$. Timbuktu and Gao were among the four localities with the lowest percentage of households consuming adequately iodized salt. These two centres are historical commercial centres that were involved in the trans-Saharan salt and gold trade. There may be economic and socio-cultural factors that influence acceptance and utilization in these areas. Knowledge of community members' perception, beliefs and acceptance of iodized salt would provide information pertinent to increasing iodized salt consumption rates in Mali. Appropriate social marketing strategies should be employed to reach hard-to-reach communities. Supporting communities to test for household salt iodine levels using simple rapid test kits would help raise consumers' awareness and decision-making abilities and inform monitoring and evaluation efforts. In addition, public-private partnerships should be engaged to explore ways to strengthen quality control measures at various importation and distribution points and to explore the possibilities of iodizing locally produced salt. 
Table 3 Socio-economic, demographic and health determinants of overweight/obese and underweight among non-pregnant women aged 19-44 years and household use of adequately iodized salt: Demographic and Health Survey data, Mali 2006t,f

\begin{tabular}{|c|c|c|c|c|c|c|}
\hline & \multicolumn{2}{|c|}{ Overweight/obese } & \multicolumn{2}{|c|}{ Underweight } & \multicolumn{2}{|c|}{ Adequate salt iodine } \\
\hline & OR & $95 \% \mathrm{Cl}$ & OR & $95 \% \mathrm{Cl}$ & OR & $95 \% \mathrm{Cl}$ \\
\hline Age (years)§ & $1 \cdot 06^{\star}$ & $1.05,1.08$ & 0.99 & $0.98,1.01$ & 0.99 & $0.98,1.00$ \\
\hline Number of other wives\| & 0.86 & $0.69,1.07$ & 0.95 & $0 \cdot 78,1 \cdot 16$ & $1 \cdot 11$ & $0.93,1.32$ \\
\hline Births in last 5 years & $1 \cdot 08$ & $0.95,1 \cdot 22$ & $0 \cdot 82^{*}$ & $0.70,0.96$ & 0.96 & $0.85,1.09$ \\
\hline Formal education (ref., no) & & & & & & \\
\hline $\begin{array}{l}\text { Yes } \\
\text { Urban residence (ref., no) }\end{array}$ & $1 \cdot 65^{\star}$ & $1 \cdot 26,2 \cdot 15$ & $0 \cdot 72$ & $0.47,1.09$ & $1 \cdot 33^{*}$ & $1.07,1.65$ \\
\hline $\begin{array}{l}\text { Yes } \\
\text { Breast-feeding (ref., no) }\end{array}$ & 0.99 & $0 \cdot 80,1 \cdot 21$ & 0.96 & $0 \cdot 78,1 \cdot 19$ & $0 \cdot 70$ & $0.49,1.01$ \\
\hline $\begin{array}{l}\text { Yes } \\
\text { Use of modern contraception (ref., no) }\end{array}$ & $0 \cdot 77^{*}$ & $0.61,0.97$ & $1 \cdot 11$ & $0.81,1.52$ & 0.92 & $0 \cdot 75,1 \cdot 13$ \\
\hline $\begin{array}{l}\text { Yes } \\
\text { Wealth index (ref., first quintile) }\end{array}$ & $1 \cdot 18$ & $0.93,1.49$ & 0.66 & $0 \cdot 36,1 \cdot 19$ & $1 \cdot 49^{*}$ & $1 \cdot 10,1 \cdot 99$ \\
\hline Second quintile & $1 \cdot 14$ & $0.77,1.68$ & $1 \cdot 06$ & $0.78,1 \cdot 44$ & 0.88 & $0.64,1.23$ \\
\hline Third quintile & $2 \cdot 28^{*}$ & $1 \cdot 47,3 \cdot 51$ & 1.00 & $0.73,1.49$ & $0 \cdot 86$ & $0 \cdot 62,1 \cdot 19$ \\
\hline Fourth quintile & $3 \cdot 15^{\star}$ & $2 \cdot 12,4 \cdot 66$ & 0.73 & $0.51,1.05$ & 0.96 & $0.68,1.35$ \\
\hline Fifth quintile & $6 \cdot 12^{*}$ & $4 \cdot 13,9 \cdot 08$ & 0.65 & $0 \cdot 36,1 \cdot 16$ & $1 \cdot 15$ & $0.68,1.94$ \\
\hline
\end{tabular}

ref., reference category.

${ }^{*}$ OR values were statistically significant $(P<0.05)$.

t $n 5668$.

‡OR and $95 \% \mathrm{Cl}$ values are estimates from logistic regression models that include all variables shown in the table.

§OR values computed for a 1-year increase in women's age.

$\|$ OR values computed for one additional wife in the household.

-OR values computed for one additional birth in the last 5 years.

Women who were breast-feeding at the time of the survey were associated with significantly lower odds of being overweight or obese. Breast-feeding mothers have higher requirements for energy and most nutrients compared with non-breast-feeding mothers ${ }^{(42,43)}$. Inability to meet these demands, as is often common in many resourcelimited low-income countries, may lead to a decrease in maternal nutritional status. Studies have reported lower body fat levels among breast-feeding mothers in lowincome nations ${ }^{(44,45)}$. High number of births in the last 5 years was significantly associated with underweight among women. Pregnancy places high nutritional demand on a mother's body which, if not met, will lead to utilization of existing body stores and eventually to loss of protein and nutrients from the body.

Limitations to these conclusions are notable. The DHS data set is primarily focused on reproductive health issues for adult women, with nutritional information data focused on children. Using secondary data in general also presents limitations, as there are only a limited number of variables to explore. There was no statistically significant association between women's BMI and household use of adequately iodized salt. It is possible that women's obesity, women's underweight and household utilization of adequately iodized salt are determined by different sets of explanatory variables. Information on respondent's knowledge of the risk of iodine-deficiency disorders and benefits of iodized salt, and on quality control measures within and outside the home, would increase our understanding of salt iodine outcomes. Availability of morbidity data and dietary intake would increase our understanding of women's BMI status as well as enable additional analysis of variables such as anaemia.

Our results show that both under- and overnutrition exist among women aged 19 to 44 years in Mali, with a greater percentage being overweight, and that the use of adequately iodized salt varies across different regions in the country. Our results also show that having a higher BMI and use of adequately iodized salt in Mali are generally correlated with other qualities that may improve quality of life (despite obesity) such as higher education, wealth, modern contraceptives and age. Previous research studies among African women have reported a social and cultural preference for a heavier and curvier body ${ }^{(16,46)}$. The problem of overweight and obesity is only beginning in Mali, as the country continues to deal with the effects of stunting, wasting and micronutrient deficiencies. Finally, these findings show the viability of merging DHS nutrition and geographic data that may be applied to other developing countries. Identifying the geographic distribution of nutritional indicators can be used to target region-specific interventions.

\section{Acknowledgements}

Source of funding: This research received no specific grant from any funding agency in the public, commercial or not-for-profit sector. Conflict of interest declaration: None. Authorship responsibilities: C.A.G., T.F.L. and L.R.P. contextualized the analysis; T.F.L. was responsible for the cartographic analysis; C.A.G. was responsible for the 
statistical analysis; and all three co-authors were responsible for the writing of the manuscript. All authors read and approved the final manuscript.

\section{References}

1. Samaké S, Traoré SM, Ba S et al. (2006) DHS-Enquête Démographique et de Santé du Mali 2006, Final Report. Bamako and Calverton, MD: CPS/DNSI and Macro International Inc.; available at http://www.measuredhs.com/ pubs/pdf/FR199/FR199.pdf

2. World Health Organization (2008) WHO Global Database on Child Growth and Malnutrition. Mali. http://www. who.int/nutgrowthdb/database/countries/who_standards/ mli.pdf (accessed July 2011).

3. Pawloski LR (2003) Mixed longitudinal analysis of growth data from Malian adolescent girls: evidence for compensatory gain. Am J Hum Biol 15, 178-186.

4. Leslie TF \& Pawloski LR (2010) Sociodemographic determinants of growth among Malian adolescent females. $A m \mathrm{~J}$ Hum Biol 22, 285-290.

5. Dettwyler KA (1992) Nutritional status of adults in rural Mali. Am J Phys Anthropol 88, 309-321.

6. Fishman C \& Golaz A (1996) Knowledge, Attitudes, Reported Practices and Anthropometric Indicators of Children's Nutritional Status. Impact Assessment of the Nutrition Communication Project as Implemented by the Ministry of Health, Solidarity and the Elderly, Africare, Save the Children, and World Vision in Dioro, Kolondieba and Koutiala. Washington, DC: USAID; available at http:// pdf.usaid.gov/pdf_docs/PNACB283.pdf

7. Dettwyler KA (1991) Growth status of children in rural Mali - implications for nutrition education programs. $A m \mathrm{~J}$ Hum Biol 35, 447-462.

8. Grosz-Ngate M (1989) Hidden meanings: explorations into a Bamanan construction of gender. Ethnology 28, 167-183.

9. Brown KH, Akhtar NA, Robertson $\mathrm{AD}$ et al. (1986) Lactational capacity of marginally nourished mothers: relationships between maternal nutritional status and quantity and proximate composition of milk. Pediatrics 78, 909-919.

10. Gewa CA, Oguttu M \& Yandell NS (2012) Maternal nutrition in rural Kenya: health and socio-demographic determinants and its association with child nutrition. Matern Child Nutr 8, 275-286.

11. Rahman M, Roy SK, Ali M et al. (1993) Maternal nutritional status as a determinant of child health. J Trop Pediatr 39, 86-88.

12. Goudet S, Griffths P \& Bogin BA (2011) Mother's body mass index as a predictor of infant's nutritional status in the post-emergency phase of a flood. Disasters 35, 701-719.

13. Fraser A, Tilling K, Macdonald-Wallis C et al. (2010) Association of maternal weight gain in pregnancy with offspring obesity and metabolic and vascular traits in childhood. Circulation 121, 2557-2564.

14. Gewa CA (2010) Childhood overweight and obesity among Kenyan pre-school children: association with maternal and early child nutritional factors. Public Health Nutr 13, 496-503.

15. Kimani-Murage EW, Kahn K, Pettifor JM et al. (2010) The prevalence of stunting, overweight and obesity, and metabolic disease risk in rural South African children. BMC Public Health 10, 158.

16. Venter FC, Walsh CM, Slabber M et al. (2009) Body size perception of African women (25-44 years) in Manguang. J Fam Ecol Consum Sci 37, 12-23.

17. McLean E, Cogswell M \& Egli I (2009) Worldwide prevalence of anaemia, WHO Vitamin and Mineral Nutrition Information System, 1993-2005. Public Health Nutr 12, $444-454$.
18. de Benoist B, McLean E, Andersson M et al. (2008) Iodine deficiency in 2007: global progress since 2003. Food Nutr Bull 29, 196-202.

19. World Health Organization (2009) Global Prevalence of Vitamin A Deficiency in Populations at Risk: 1995-2005. WHO Global Database on Vitamin A Deficiency. Geneva: WHO; available at http://whqlibdoc.who.int/publications/ 2009/9789241598019_eng.pdf

20. Zimmermann MB (2009) Iodine deficiency in pregnancy and the effects of maternal iodine supplementation on the offspring: a review. Am J Clin Nutr 89, issue 2, 668S-672S.

21. MEASURE DHS/ICF International (2009) Demographic and Health Surveys Methodology. Training Field Staff for DHS Surveys. http://measuredhs.com/pubs/pdf/DHSM3/Training_ Field_Staff_for_DHS_Surveys_Oct2009.pdf (accessed August 2012).

22. MEASURE DHS/ICF International (2012) Demographic and Health Surveys Methodology. Biomarker Field Manual. http://www.measuredhs.com/pubs/pdf/DHSM7/DHS6_ Biomarker_Manual_9Jan2012.pdf (accessed August 2012).

23. Rustein SO \& Johnson K (2004) The DHS Wealth Index, DHS Comparative Reports No. 6. http://www.measuredhs. com/pubs/pdf/CR6/CR6.pdf (accessed December 2010).

24. Bouvier P, Papart JP, Wanner P et al. (1995) Malnutrition of children in Sikasso (Mali): prevalence and socio-economic determinants. Soz Praventivmed 40, 27-43.

25. Vella V, Tomkins A, Borghesi A et al. (1992) Determinants of child nutrition and mortality in north-west Uganda. Bull World Health Organ 70, 637-643.

26. Otten JJ, Hellwig PZ \& Meyers LD (eds) (2006) Dietary Reference Intakes: The Essential Guide to Nutrient Requirements. Washington, DC: National Academy Press.

27. Butte NF \& Hopkinson JM (1998) Body composition changes during lactation are highly variable among women. J Nutr 128, 2 Suppl., 381S-385S.

28. Merchant K, Martorell R \& Haas JD (1990) Consequences for maternal nutrition of reproductive stress across consecutive pregnancies. Am J Clin Nutr 52, 616-620.

29. Marcoux R (1997) Nuptialite et maintien de la polygamie en milieu urbain au Mali. Cah Que Demogr 26, 191-214.

30. Pawloski LR \& Kitsantas P (2008) Classification tree analysis of stunting in Malian adolescent girls. Am J Hum Biol 20, 285-291.

31. Worthington-Roberts BS \& Williams SR (1996) Nutrition Throughout the Lifecycle, 3rd ed. St. Louis, MO: Mosby.

32. Watson DF \& Philip GM (1985) A refinement of inverse distance weighted interpolation. Geo-Processing 2, 315-327.

33. Achilleos $G$ (2008) Errors within the inverse distance weighted (IDW) interpolation procedure. Geocarto Int $\mathbf{2 3}$, 429-449.

34. Abubakari AR, Lauder W, Agyemang C et al. (2008) Prevalence and time trends in obesity among adult West African populations: a meta-analysis. Obes Rev 9, 297-311.

35. Hightower AW, Ombok M, Otieno R et al. (1998) A geographic information system applied to a malaria field study in western Kenya. Am J Trop Med Hyg 58, 266-272.

36. Entwisle B, Rindfuss RR, Walsh SJ et al. (1997) Geographic information systems, spatial network analysis, and contraceptive choice. Demography 34, 171-187.

37. Rosero-Bixby G (2004) Spatial access to health care in Costa Rica and its equity: a GIS-based study. Soc Sci Med 58, 1271-1284.

38. Global Micronutrient Project (not dated) Iodine Situation in Mali. New Orleans, LA: Tulane University; available at http:// www.tulane.edu/ internut/Countries/Mali/maliiodine.html

39. Jamison DT, Feachem RG, Makgoba MW et al. (editors) (2006) Disease and Mortality in Sub-Saharan Africa, 2nd ed. Washington, DC: The World Bank; available at http://www.dcp2.org/file/66/Disease\%20and\%20Mortality\% 20 in $\% 20 S S A . p d f$ 
40. Stephenson R, Baschieri A, Hennink M et al. (2007) Contextual influences on modern contraceptive use in Sub-Saharan Africa. Am J Public Health 97, 1233-1240.

41. Pawloski LR, Shier NW, Fernandez XE et al. (2003) Examination of urinary iodine status from a sample of Malian adolescent girls. Afr J Food Agric Nutr Dev 3, 20-28.

42. Dewey KG (1997) Energy and nutrient requirements during lactation. Annu Rev Nutr 17, 19-36.

43. Institute of Medicine (2001) Dietary Reference Intakes for Vitamin A, Vitamin K, Arsenic, Boron, Chromium, Copper, Iodine, Iron, Manganese, Molybdenum, Nickel, Silicon, Vanadium, and Zinc: A Report of the Panel on Micronutrients, Subcommittees on Upper Reference Levels of
Nutrients and of Interpretation and Uses of Dietary Reference Intakes, and the Standing Committee on the Scientific Evaluation of Dietary Reference Intakes. Washington, DC: National Academy Press.

44. Dorea JG (1997) Changes in body weight and adiposity during lactation. Nutr Res 17, 379-389.

45. Winkvist A \& Rasmussen KM (1999) Impact of lactation on maternal body weight and body composition. J Mammary Gland Biol Neoplasia 4, 309-318.

46. Puoane T, Fourie JM, Shapiro M et al. (2005) Big is beautiful' - an exploration with urban black community health workers in a South African township. S Afr J Clin Nutr 18, 6-15. 